\title{
Students with Disabilities at Two Higher Education Institutions Selected from South Africa: A Social Model of Disability
}

\author{
Mogomme Alpheus Masoga ${ }^{1} \&$ Rose Satsope Maoto ${ }^{2}$ \\ ${ }^{1}$ Faculty of Arts, University of Zululand, South Africa \\ ${ }^{2}$ Faculty of Humanities, University of Limpopo, South Africa \\ Correspondence: Mogomme Alpheus Masoga, Faculty of Arts, University of Zululand, South Africa.
}

Received: May 14, 2021

Accepted: October 12, 2021

Online Published: October 13, 2021

doi:10.5430/ijhe.v10n6p238

URL: https://doi.org/10.5430/ijhe.v10n6p238

\begin{abstract}
Learners with disabilities are faced with unprecedented challenges in their pursuit of integration in the institutionalized higher education system in South Africa. The aim of this paper is to explore the recruitment and integration of students with disabilities (SWDs) at selected rural universities in South Africa in terms of facilities for physically challenged students. Personal conversations and informal discussions and desk and documentary research have collectively informed the present discourse. By utilizing a social model of disability, this study proposes that both institutions need to accelerate the provision of user-friendly facilities to accommodate various categories of SWDs either currently enrolled or those aspiring to study at the institutions. Considering the evaluations and observations explored in this opinion paper, the academic community of both institutions will need to pay attention to the special needs of SWDs because the absence of this attention will negatively impact the outcome of the academic life of learners.
\end{abstract}

Keywords: education, disability, higher institutions, South Africa

\section{Introduction}

Disabilities of various types are found everywhere in the world: vision and hearing impairment, mental health conditions, intellectual disability, acquired brain injury, autism spectrum disorder, and various physical disabilities (Rugwiji, 2012). Hutcheon and Wolbring (2012) have affirmed that SWDs face physical, social, and emotional barriers in their postsecondary education. In most parts of the world, people with disabilities (PWDs) constitute the underrepresented minorities (Lau, 2003), members of the oppressed group subjugated by "able-bodied" ideologies encoded into large social structures (Schipper, 2006). In Africa, there is a multiplicity of interpretations of disability (Berghs, 2017). Some people believe that disability happens due to witchcraft (Fountaine, 1996; Rugwiji, 2012). Such belief systems have unwittingly infiltrated institutions of higher learning as divergent modus operandi (Department of Higher Education and Training [DHET], 2018). One could ask whether all institutions of higher learning in South Africa are aware of the nature of prospective students who apply to study in their universities.

In this case, one must keep in mind the DHET (2018) Strategic Disability Framework for the Post-School Education and Training System, which aims to "guide the improvement of access to and success in post-school education and training (including at private institutions) for people with disabilities" (p. i). Interestingly, this strategic framework adopted a social model of disability, thereby providing a "more critical interpretation of disability as a form of social inequality or disadvantage resulting from oppressive social structures and processes, rather than from individual differences" (DHET, 2018). Fundamentally, the social model of disability wrestles with critical concerns of equality (DHET, 2018). Serious questions such as the following are central in this conversation: How can barriers that restrict life choices for people with disabilities be removed? How can people with disabilities be independent and equal in society with choice and control over their lives? (DHET, 2018). To this end, the focus of this paper is based on the observation that if all universities knew prior to accepting students, relevant facilities could be installed in preparation for certain categories of students, such as SWDs. One could also argue that lack of preparing appropriate facilities for the enrolment of SWDs is a deliberate move to raise prejudice against certain categories of potential students (cf. Bornman \& Rose, 2010). Hence, Jama et al. (2008) have raised the following question: "Do stakeholders really know who these learners (prospective students) are before" receiving them? This study attempts 
to explore the recruitment and integration of SWDs at the University of Venda (Univen) and the University of Limpopo (UL) in terms of facilities for physically challenged learners.

\section{Stating the Problem}

The following observations have noted two problems requiring some investigation:

1) In recent years, scholarship on disability contestations has been scanty. Where contributions have been submitted, the thrust on justice and anti-discriminatory mode regarding entrance of SWDs into institutions of higher learning in South Africa has not been given optimal attention (Rugwiji, 2012).

2) Notably, narratives of recruitment and integration and the establishment of user-friendly facilities for SWDs at Univen and UL are currently unsatisfactory. The abovementioned observations present the problem discussed here.

\section{The Motivation}

This paper has been motivated largely by our personal encounters and familiarization with SWDs at Univen and UL who needed our services in various ways. Some of these services include access to Internet services on campus to conduct research, library access, and use of facilities at the library. However, we are not trained disability specialists expected to either guide or assist these students. For example, on two separate occasions, two visually impaired students requested our assistance:

1) Visually impaired students came to our offices to be assisted with reformulating their research proposals, which we lucidly declined because we felt it would be unethical and plagiaristic because it entailed writing down on their behalf in the absence of their writing apparatus.

2) A visually impaired postdoctoral fellow asked for assistance in processing his work permit.

In both cases, we inquired from the candidates themselves whether equipment and facilities are available at Univen and UL for visually impaired learners. The candidates responded that they did not know. It should be mentioned that there is a degree of difference in comparing both universities (UL and Univen). Univen is currently battling to adapt its programme to assist SWDs to nondiscriminatory learning. Conversely, the UL has established a center that focuses on SWDs called Reakgona Centre for Disability. In both instances, SWDs still raised concerns about how they were not fully integrated into the teaching and learning programmes of these universities.

Personal interviews, informal discussions, and desk and documentary research have collectively informed the present discourse. A few people (including prospective students) from whom we solicited personal opinions and perceptions about SWDs at Univen and UL have expressed the need to be accommodated. In addition, as researchers and scholars, we take informal discussions and anecdotes seriously because they both inform our scholarly debate in a unique way. We also admit that desk and documentary research (articles, books, and the Internet) occupy a large portion of our data pool. The research approach involves analyzing key documents for this study.

The location of classrooms at the two mentioned institutions is commendable, especially for SWDs on wheelchairs. However, a reading apparatus for visually impaired students must be prioritized. The recruitment of specialist lecturers in sign language must be a continuous exercise toward the enrolment and teaching of prospective students with hearing challenges. These challenges and concerns are summarized as follows:

- No elevators provided for students with disabilities to be able to access some learning facilities on campus

- No brail practitioner and expert to assist with the preparation of exam papers

- Most campus surfaces are not smooth for using equipment such as a wheelchair

- Student access cards and meal cards are not user friendly for most students with disabilities

\section{The Social Model of Disability and Its Function}

In discussing the place and role of the social model of disability (SMD), we propose to look at three challenges: attitudinal, environmental, and organizational. In the past, the medical model of disability has viewed people as being different, impaired, or disabled and that their needs could be fixed by medical or other such treatments. In response to that model, the SMD looks at individuals' strengths and needs and holds society accountable for placing barriers to their progress and aspirations. For this purpose, we have opted for the SMD. It should also be mentioned that according to this model, disability is caused by the society in which one lives and is not the "fault" of an individual person with disability (Rugwiji, 2012). The SMD that Schipper (2006) has chosen to describe as the minority model of disability (p. 7) has been developed by people with disabilities in response to the medical model and the impact it has had on their lives (Rugwiji, 2012). For Rugwiji (2012), the social model takes into account 
people with a disability as part of economic, environmental, and cultural society collectively as a "social inclusion" (O'Halloran, 2007). For Reinders (2008), the SMD directs one attention to the particularities of society rather than to the particularities of being human.

The SMD seeks to sensitize societies to re-evaluate their perceptions of PWDs as they make attempts to remove barriers and constraints that prohibit social interactions that deny social inclusion. Peters et al. (2009) maintained that SMD has been a social tool to shift the focus of disability as individual deficit to disability as a social construction in an oppressive society. The SMD can also be complemented by the medical model of disability (MMD), which sees the person with a disability as the problem, and not society. Schipper (2006) explained that the MMD understands disability as a biological defect within a person's body that needs to be cured. For Fallon (2007), the MMD is a socio-political model by which illness or disability, being the result of a physical condition and which is intrinsic to the individual, may reduce the individual's quality of life and cause clear disadvantages to the individual. Traditional Bantu African practices are non-racial in character (Joubert, 2014). Bantu cultures are inclusive, as much as they are collective and communal to maintain Ubuntu (Sibanda, 2014). It is perhaps the same line of thinking that informed Berghs's (2017) affirmation of Ubuntu as an African humanist and ethical world view where disability, as part of a common humanity, is necessarily part of what makes us human (p. 2). It is the concept of Ubuntu that allows the identification of African social ethical discourses and practices countering colonialism, disablement, and oppression (Berghs, 2017). However, during apartheid in South Africa, the Bantu Education Act (No. 47 of 1953) classified and separated education along racial lines (Mdepa \& Tshiwula, 2012). In the same way, the adoption by so-called "educated" and "civilized" Africans who have over the years of colonial domination been exposed to Western ideologies and worldviews that are largely ethnocentric. In this case, ethnocentrism is described by Nalane (2011) as the tendency to believe that one's ethnic or cultural group is centrally important (superior) and that all other groups are measured in relation to one's own. Any view individuals or society upholds is based on their understanding as dictated by their culture and beliefs (worldview).

In this regard, Nalane (2011) reiterated that this has influenced people to shun their own cultural values and customs in favour of the former. This adoption has led to the deprivation and depletion of numerous African cultural values and norms (Sibanda, 2014) that are not only educative and ethical but also regard human life as sacred. When such value systems are shunned and isolated in the teaching of a growing child, the growing youth who would themselves become adults, would be deprived of the very essence of humanness. Such value systems usually characterize distinctive African culture and lifestyle, hence cultural relativism ("the principle that an individual human's beliefs and activities should be understood in terms of his or her own culture"). Furthermore, Naidoo et al. (2017) concurred that social marginalization and material deprivation add to PWDs' limited access to education and infrastructural challenges, such as poor roads, costly transport, inaccessible terrains, and poor access to health services, and contribute toward their feelings of powerlessness, vulnerability, and lack of voice. The abovementioned argument demonstrates the notion of avoidance by some African societies of those who are regarded as "incomplete" because they carry in their bodies some form of physical impairment (Rugwiji, 2012). An example of this is a person who is visually impaired. The society of able-bodied humans should desist from oppressing, marginalizing, and culturally imperializing those who are different physically, psychologically, and materially (Young, 2004). Desisting from these would mean a change of attitude and a willingness to consider all humans as complete in all senses but differently abled. In this case, appropriate policies and programmes could be introduced to change both attitude and practice in dealing with persons with disabilities. Hence, Young (2004) further reiterated that marginalization is the act of relegating or confining a group of people to a lower social standing or edge of society.

Indeed, the social, educational, cultural, linguistic, religious, and racial diversity of South African education society should find expression within institutions of higher education (Cross 2004). However, the extent to "how" this is happening at the Univen and UL needs further consideration. Although diversity has recently dominated numerous academic discourses, methodological "approaches" as the way forward have not been interrogated sufficiently. Hence, Cross (2004) remarked that today in South Africa, there are few scholars who have dedicated their scholarship with the intention of directly intervening in social problems. In the same way, Matshedisho (2007), who complements Cross's opinion, indicated that not all institutional policies are formal in the sense of being recognized and adopted by universities, and in this view, Univen and UL are no exception. Some universities, in a sense, de-campaign against diversity by "refusing" to recognize that "a person could be intelligent in numerous ways" (Barrington, 2004). Having said that contestations of skills exhibited in sporting activities, for example, are interrogated in the debate on knowledge economy because in some parts of the world, sporting activities such as soccer, tennis, rugby, cricket, and basketball are survival skills that are learned at various sporting academies. 


\section{Discussion}

The three challenges or barriers have been identified as attitudinal, environmental, and organizational. These challenges are in line with the SMD. All society is required to change. The first change involves attitudes - the attitudes of society toward people with disabilities and "sincere" acknowledgement of value of the potential quality of life of PWDs (DHET, 2018). The second challenge, environmental, involves support for PWDs. Part of these supports should include access to basic services, information, and facilities (DHET, 2018). It could be included in the category referred to as access to information in suitable formats (DHET, 2018). The environment should be conducive to and exude a positive ambience of support and reception. The organizational challenge refers to the preparedness and commitment of institutions, such as those of higher education, in providing appropriate physical structures and putting in place policies that support and enhance inclusion, mainstreaming changing attitudes and training and monitoring processes and systems aimed at providing the value of the potential quality of life of people with disabilities. These three challenges become central in taking this process forward. It is argued that, generally, in Africa, discrimination against and/or exclusion of certain categories of people based on their ethnic belonging, identity, or social and/or disability status is not only becoming widespread but is also a deep-rooted practice. Africans are naturally anti-individualistic (Van Dyk \& De Kock, 2004); individualism is slowly emerging due to interaction with non-African cultures (Mdepa \& Tshiwula, 2012; Rugwiji, 2014).

In the last few years, some scholars (Mdepa \& Tshiwula, 2012) have argued that the extent to which one has been exposed to oppression and/or discrimination, that individual is likely to exert the same practice on other people because an oppression concept tends to be a school of thought that one enjoys practicing-reversal oppression. Clearly, the SMD has a significant role to play in advocating for the rights of PWDs and in exposing the ableism so prevalent in society (Young \& Berry, 2016). Hence, Rugwiji (2012) has opined that in modern societies, some guardians or parents hide their PWDs from the public because they feel ashamed to be identified with them. Rugwiji believed this is due to the popular belief that a disability is a "shameful" abnormality that is the result of a misdeed within the family or that they have been bewitched. As Rugwiji opined, such misconceptions are some of the motivating factors that accentuate the killing of babies born with some form of physical impairment (p. 91), as discriminating against PWDs at schools and universities and in workplaces.

Article 24 of the United Nations Convention on the Rights of PWDs (CRPWD) states that all PWDs should be afforded the right to education as postulated in the right to education for children with disabilities in South Africa. South Africa has ratified the CRPD without reservations and therefore is bound by its provisions in the right to education for children with disabilities in South Africa. In addition, the South African Constitution affords the right to education for "everyone" as stipulated in its Integrated national disability strategy. Furthermore, Clause 8 (1) of the Bill of Rights clearly states that PWDs are constitutionally protected. The same observation is also shared by Matshedisho (2007), who stated that general national anti-discrimination legislation and policy inform the formulation of specific policies that protect students with disabilities such as access to learning. On the employment market, Statistics South Africa (2014) reaffirmed that Article 27 of the CRPD places specific obligations on governments to promote equal access to employment for PWDs.

It would be instructive for both the UL and Univen to address the abovementioned challenges. The following steps are necessary to take this process forward. First, a serious recast of the policy environment of these two institutions is critical. A change of attitudes would require appropriate legal instruments and policies to take effect. All levels of the university management should be involved in this whole process. At some point training and development of staff would become necessary as well as the recruitment of the right personnel with the requisite skills and understanding of disability issues in a higher education environment. Budgeting in keeping with the commitment for inclusion of people with disabilities is important. The latter should also address the infrastructure of the university. This aspect should not be treated as an after-thought but, instead, mainstreamed throughout the entire process of the university's planning and management. We are proposing a total rethinking in terms of the institutional operations, formal conversations, and implementations of a university. This becomes a necessary journey for most universities. Further, sharing of knowledge among learners at Univen and UL should include providing access to appropriate classrooms, textbooks, and so on for SWDs. Furthermore, Dikotla et al. (2014) rightly observed that managing and sharing of knowledge is the focus of modern organizations because knowledge is the primary factor of production rather than capital and labour. Putting the above statement into context, sharing knowledge with SWDs in South Africa enhances productivity. To sufficiently substantiate Barrington's (2004) analysis, we will discuss a practical example of sporting activities in view of diversity and knowledge of the economy in Africa. In South Africa there is an attempt to ensure that the production of knowledge should follow certain conventional patterns because those already in academia have exhausted their knowledge production base so much that new thought patterns and "traditional 
academic intelligences are held in low self-esteem and their strengths may return unrealized and lost to both the institution and society at large" (Barrington, 2004). In contrast, in other parts of the world (for example, Spain, England, Brazil, and Portugal), knowledge economy that manifests in soccer skills have continued to catapult two critical aspects: accumulation of gross domestic product and enhancement of development for respective soccer nations and improvement of living standards for individual players and their families.

Africa, Cameroon, South Africa, Tunisia, Egypt, Nigeria, Ghana, Morocco, and Zambia, among others, are known as footballing nations. A boy who exhibits some aptitude and spatial intelligence in soccer is promoted to mature in it and, eventually, graduate as a professional footballer. Kunz (2006) commented that about 265 million people play football worldwide. The list of soccer legends who will be playing football for the rest of their life is endless. Other sports in which knowledge economy is exhibited include tennis, rugby, volleyball, and cricket. In addition to becoming an academic, medical doctor, or legal practitioner, among others, there are various other sporting activities in which SWDs can be coached into becoming professionals like others all over the world. In this view, it is possible that if knowledge is managed properly_-"knowledge management" as Dikotla et al. (2014) opined-Univen and UL are strategically positioned to play a critical role of promoting knowledge production among SWDs, which will go a long way in either their academic career, if they choose to pursue that avenue, or in becoming a professional sports persons. Sporting programmes in which SWDs can be coached include road race $(20 \mathrm{~km}, 40 \mathrm{~km}$, etc.), wheelchair basketball, rugby, soccer, wheelchair slalom, goal ball, and netball. The criterion for selecting the sporting candidates comprises assessment of the nature of disability of an individual. Visually impaired learners may be streamlined in other nonsporting programmes. The stadia and other sporting facilities need to be constructed in such a way that they are easily accessible by PWDs. For some, finding funding to accommodate programmes meant for SWDs may appear a mammoth task. Nevertheless, in our view, when a carefully drafted plan of action and a project budget are presented to members of the public and/or funding organizations, responses to such a noble cause will not only be overwhelming but will also demonstrate the commitment of the academic community toward community engagement (Russell, 2008) as the long-term plan of the institution in terms of diversity.

\section{Conclusion}

Considering the evaluations and observations explored in this essay, the academic community at Univen and UL will need to pay attention to exploring recruitment and integration of SWDs at their institutions in light of adapting facilities for physically challenged students. The main challenges have been identified as attitudinal, environmental, and organizational. In this regard, there are several areas that need to be addressed. First, research on the implementation of user-friendly facilities must be given its merit, unless such claims are made clumsily against evidence of the availability or existence of such structures at Univen and UL. Second, helping to improve the situation of SWDs at Univen and UL should not be emancipatory in character, but should aid the elimination of the "vicious circle of poverty" (Mosley \& Verschoor, 2005). Third, a social model of disability should be considered in view of the challenges faced by SWDs. Fourth, moral and psychosocial support is needed by both PWDs and their parents/relatives so that they graduate with an understanding and acceptance of the reality of disability that has affected one of their own. Fifth, institutional grants should be made available for SWDs so that they realize their potential, especially by being cognizant of the fact that most of them hail from poverty-stricken backgrounds. It is critical for IHL in South Africa to adhere to legal implications, including for the installation of facilities, regarding enrolling SWDs because they are protected by law. In terms of diversity, able-bodied learners at Univen and UL should adopt a culture of sharing ideas and interacting with SWDs as a way of promoting an academic environment that is not based on racial discrimination, prejudice, or, particularly, disability.

\section{Acknowledgments}

The PGDip (HE) programme of the University of Kwa-Zulu Natal, in particular the module diversity that looked among other areas-Disability and Inclusion at Higher Institutions of Learning.

\section{References}

Antonio, A. L. et al. (2004). Effects of racial diversity on complex thinking in college learners. Research Report, 15(8), 507-510. https://doi.org/10.1111/j.0956-7976.2004.00710.x

Arellano, E., Valentine, K., Prentice, M., \& Torres, M. F. (2012). The importance of student cross-racial interactions as part of college education: Perceptions of faculty. Journal of Diversity in Higher Education, 5(4), 191-206. https://doi.org/10.1037/a0030109

Barrington, E. (2004). Teaching to student diversity in higher education: How multiple intelligence theory can help. Teaching in Higher Education, 9(4), 421-434. https://doi.org/10.1080/1356251042000252363 
Berghs, M. (2017). Practices and discourses of Ubuntu: Implications for an African model of disability? African Journal of Disability, 6, 1-8. https://doi.org/10.4102/ajod.v6.292

Borg, I., \& Shye, S. (1995). Facet theory: Form and content. Sage.

Bornman, J., \& Rose, J. (2010). Believe that all can achieve: Increasing classroom participation in learners with special support needs. Van Schaik.

Cross, M. (2004). Institutionalizing campus diversity in South African higher education: Review of diversity scholarship and diversity education. Higher Education, 47, 387-410. https://doi.org/10.1023/B:HIGH.0000020854.04852.80

Department of Higher Education and Training. (2018). Strategic policy framework on disability for the post-school education and training system.

Dikotla, M. A., Mahlatji, M. R., \& Makgahlela, L. A. (2014). Knowledge management for improvement of service delivery in South Africa's municipalities. Journal of Public Administration, 49(3), 847-859.

Fallon, A. (2007). Medical model of disability. http://enabledisability.wordpress.com/2007/02/21/medical-model-of-disability

Fezekile Futhwa, N. (2011). Setho: Afrikan thought and belief system. CreateSpace Independent Publishing Platform.

Fountaine, R. C. (1996). Disabilities and illness in the Bible: A feminist perspective. In A. Brenner (Ed.), A feminist companion to the Hebrew Bible in the New Testament, 21-26. Sheffield Academic Press.

Gurin, P., Dey, E., Hultado, S., \& Gurin, G. (2002). Diversity and higher education: Theory and impact on educational outcomes. Harvard Educational Review, 72(3), 330-366. https://doi.org/10.17763/haer.72.3.01151786u134n051

Hutcheon, E. J., \& Wolbring, G. (2012). Voices of "disabled" postsecondary learners: Examining higher education "disability" policy using an ableism lens. Journal of Diversity in Higher Education, 5(1), 39-49. https://doi.org/10.1037/a0027002

Jama, M. P., Mapesela, M. L. E., \& Beylefeld, A. A. (2008). Theoretical perspectives on factors affecting the academic performance of learners. South African Journal of Higher Education, 22(5), 992-1005. https://doi.org/10.4314/sajhe.v22i5.42919

Joubert, R. (2014). Race classification and equal educational opportunities in South African schools. International Journal of Educational Leadership Preparation, 1, 41-53.

Kunz, M. (2006). 265 million playing football. FIFA Magazine Big Count, 11-13.

Lau, L. K. (2003). Institutional factors affecting student retention. Education Fall, 124(1), 126-135. http://Ib17.epnet.com?DeliveryPrintSave.asp

Matshedisho, K. R. (2007). Access to higher education for disabled learners in South Africa: A contradictory conjecture of benevolence, rights and the social model of disability. Disability \& Society, 22(7), 685-699. https://doi.org/10.1080/09687590701659535

Mdepa, W., \& Tshiwula, L. (2012). Student diversity in South African higher education. Widening Participation and Lifelong Learning, 13, 19-33. https://doi.org/10.5456/WPLL.13.S.19

Mosley, P., \& Verschoor, A. (2005). Risk attitudes in the vicious circle of poverty. European Journal of Development Research, 17(1), 59-88. https://doi.org/10.1080/09578810500066548

Naidoo, D., Van Wyk, J., \& Joubert, R. (2017). Community stakeholders' perspectives on the role of occupational therapy in primary healthcare: Implications for practice. African Journal of Disability, 6(0), 1-12. https://doi.org/10.4102/ajod.v6i0.255

Ned, U., \& Lorenzo, T. (2016). Enhancing the public sector's capacity for inclusive economic participation for disabled youth in rural communities. African Journal of Disability, 5(1), 1-5. https://doi.org/10.4102/ajod.v5i1.189

O'Halloran, K. (2007). Charity law and social inclusion: An international study. Routledge. https://doi.org/10.4324/9780203640142

Peters, S., Gabel, S., \& Symeonidou, S. (2009). Resistance, transformation and the politics of hope: Imagining a way forward for the disabled people's movement. Disability \& Society, 24(5), 543-556. 
https://doi.org/10.1080/09687590903010875

Reinders, S. H. (2008). Receiving the gift of friendship: Profound disability, theological anthropology, and ethics. William B. Eerdmans Publishing.

Rugwiji, T. (2012). Rereading the David-Mephibosheth narrative from a pastoral hermeneutics: A social model. Scriptura, 109, 82-95. https://doi.org/10.7833/109-0-126

Rugwiji, T. (2014). Towards the quest for transforming Old Testament scholarship: The impact of political and socio-economic crises on scholarship in Zimbabwe. Old Testament Essays, 27(3), 1009-1034.

Russell, N. (2008). The active community engagement continuum. The ACQUIRE Project Paper. USAID.

Schipper, J. (2006). Disability studies and the Hebrew Bible: Figuring Mephibosheth in the David story. T\&T Clark.

Sibanda, P. (2014). The dimensions of "hunhu/ubuntu" (humanism in the African sense): The Zimbawean conception. IOSR Journal of Engineering, 4(1), 26-29. https://doi.org/10.7833/109-0-126

Statistics South Africa. (2014). Census 2011: Profile of PWDs in South Africa. Statistics South Africa.

Van Dyk, G. A., \& De Kock, F. S. (2004). Relevance of the individualism-Collectivism (IC) factor for the management of diversity in the South African national defence force. SA Journal of Industrial Psychology, 30(2), 90-95. https://doi.org/10.4102/sajip.v30i2.155

Young, I. (2004). Five faces of oppression. In L. Heldke \& P. O’Oconnor (Eds.), Oppression, privilege and resistance. McGraw-Hill.

Young, L. S., \& Berry, J. (2016). Shipping and holding minds: A psychosocial analysis of material subjectivity in relation to childhood disability. African Journal of Disability, 5(1), 1-9. https://doi.org/10.4102/ajod.v5i1.266

\section{Copyrights}

Copyright for this article is retained by the author(s), with first publication rights granted to the journal.

This is an open-access article distributed under the terms and conditions of the Creative Commons Attribution license (http://creativecommons.org/licenses/by/4.0/). 